\title{
Propaganda y educación. Criterios de diferenciación conceptual y comunicacional
}

\author{
Antonio PINEDA CACHERO ${ }^{1}$ \\ Universidad de Sevilla
}

\begin{abstract}
RESUMEN:
El objetivo de este trabajo es proponer criterios conceptuales para distinguir entre la educación y la propaganda. Las relaciones entre ambas pueden estudiarse desde distintas perspectivas: las ocasiones históricas en que la educación ha sido instrumentalizada propagandísticamente, la concepción de la educación como una herramienta defensiva ante la propaganda, la identificación de educación y propaganda, etc. Desde nuestro punto de vista, propaganda y educación son dos fenómenos distintos que pueden diferenciarse desde la intención comunicativa que mueve a cada una de ellas.
\end{abstract}

PALABRAS CLAVE: Propaganda; Educación; Intención comunicativa; Teoría de la propaganda; Poder

TITLE: Propaganda and education. Criteria for conceptual and communicational differentiation.

\begin{abstract}
:
The aim of this paper is the proposal of conceptual criteria in order to distinguish between education and propaganda. The relationships between them may be studied from different perspectives, such as the historical moments when education has been propagandistically instrumentalized, the notion of education as a defensive tool against propaganda, their identification, and so on. From our point of view, propaganda and education are different phenomena that can be distinguished if we consider the different communicative intentions behind each of them.
\end{abstract}

KEY WORDS: Propaganda; Education; Communicative Intention; Propaganda Theory; Power

\section{Introducción}

El objetivo de este artículo es proponer principios conceptuales para establecer una distinción teórica entre propaganda y educación, entendidas ambas como fenómenos comunicativos. Como marco teórico referente a la propaganda nos apoyamos en la conceptualización propuesta en el libro Elementos para una teoría comunicacional de la propaganda ${ }^{2}$. En cuanto a la educación, se trata de un fenómeno que ha sido defini-

1 Profesor Titular de la Universidad de Sevilla. Imparte asignaturas en la Facultad de Comunicación sobre comunicación y publicidad. Entre sus líneas de investigación se encuentran la Teoría de la Propaganda y la Semiótica de la Publicidad. Correo electrónico: apc@us.es

El autor quiere expresar su agradecimiento a los evaluadores del artículo por los comentarios y sugerencias realizados.

2 Cfr. Pineda CACHERO, A. (2006): Elementos para una teoría comunicacional de la propaganda, Alfar, Sevilla. 
do en muchas ocasiones, y desde criterios distintos ${ }^{3}$. Nuestro objetivo no es ofrecer una definición de educación, sino aportar argumentos que permitan, como mínimo, deslindar lo que sería una educación propagandística de una educación no-propagandística. Obviamente, partimos para ello de un cierto sentido de lo que es, o debería ser, la educación, pero eso no equivale a ofrecer una definición cerrada del fenómeno educativo, tarea que consideramos más propia de la teoría y la filosofía de la educación.

Conceptualmente, nuestra labor consistirá en intentar deslindar a la educación de la propaganda desde el enfoque de la Teoría de la Propaganda. ¿Por qué este enfoque conceptual? Además del interés que pueda tener tanto para los educadores profesionales como para las Ciencias de la Información y la Comunicación (y en particular para la comunicación propagandística y fenómenos afines, como la publicidad comercial), existe un factor clave en nuestra indagación: la importancia que suele imputársele a la educación en la literatura sobre propaganda, hasta el punto de que (aunque no suele estudiarse como materia específica en el ámbito científico de la Información y la Comunicación) la educación es un fenómeno frecuentemente confundido o identificado con el fenómeno propagandístico. De hecho, es un tema que aparece con frecuencia en las reflexiones acerca de la propaganda ${ }^{4}$. Por otro lado, tampoco puede negarse el uso empírico de la educación con fines de propaganda, es decir, las frecuentes ocasiones históricas en que el sistema educativo ha sido instrumentalizado con fines de poder.

Por todo ello, consideramos interesante afrontar el objetivo de investigación desde el ámbito de la Teoría de la Propaganda. La pregunta clave sería: dadas las propiedades conceptuales del fenómeno propagandístico, ¿qué condiciones debería cumplir la educación para poder distinguirse del fenómeno anterior? Nuestro objetivo, por consiguiente, es de naturaleza teórica: en tanto que fenómenos comunicativos, ¿cuál es el criterio que distingue a la propaganda de la educación? Antes de profundizar en nuestra propuesta conceptual, revisamos de manera general las relaciones entre educación y comunicación y, más específicamente, algunas de las formas que pueden adquirir las relaciones entre educación y propaganda.

3 Cfr. García Aretio, L. (1989): La Educación, Madrid, Paraninfo, 14-19; GARCía CARRASCO, J., y García del Dujo, Á. (1996): Teoría de la educación. I. Educación y acción pedagógica, Salamanca, Ediciones Universidad de Salamanca, 46-55.

4 Cfr. Lasswell, H. D. (1927): «The Theory of Political Propaganda», The American Political Science Review, vol. 21, 1927, 628; LuMLEY, F. E. (1933): The Propaganda Menace, Nueva York y Londres, D. Appleton-Century Company, Inc., 301-329; DRIENCOURT, J. (1964): La propaganda, nueva fuerza política. Traducción castellana de Inés Oyuela de Estrada. Buenos Aires, Editorial Huemul, 45-49; Lasswell, H. D. (1969): «The Study and Practice of Propaganda», en Lasswell, H. D., Casey, R. D., y Smith, B. L. (eds.): Propaganda and Promotional Activities. An Annotated Bibliography, The University of Chicago Press, 3; PIZARROSO Quintero, A. (1990): Historia de la propaganda. $2^{\mathrm{a}}$ edición, ampliada. Madrid, Eudema, 1993, 32-33; HUICI MóDENES, A. (2010): Guerra y propaganda en el siglo XXI. Nuevos mensajes, viejas guerras., Sevilla, Alfar, 160-163. 


\section{Las relaciones entre educación y comunicación como marco}

El suelo común disciplinar para reflexionar sobre educación y propaganda radica en la comunicación. La propaganda es un fenómeno comunicativo, y lo mismo sucede con la educación, que no puede entenderse sin un proceso de comunicación entre el educador y el educando ${ }^{5}$. Así, la educación puede verse como un proceso de comunicación $^{6}, y$, viceversa, la comunicación se ha visto como un fenómeno educativo ${ }^{7}$. Esta imbricación profunda entre ambos fenómenos trasciende, de hecho, lo puramente instrumental: según José Ignacio Aguaded Gómez, «la Educación y la Comunicación se vuelven, cada vez más, un binomio inseparable, por encima mismo de los propios medios, técnicas e instrumentos comunicativos empleados» ${ }^{8}$. Así, la educación para los medios de comunicación supone un área específica de programación educativa ${ }^{9}$. También se ha señalado el papel educativo que cumplen los medios de comunicación, más allá de la programación estrictamente educativa ${ }^{10}$.

Pero no sólo puede verse la educación como un proceso de comunicación, sino que puede reflexionarse asimismo sobre un modelo de comunicación específico dirigido a la educación ${ }^{11}$. En otras palabras, junto a la educación como proceso de comunicación existe el fenómeno de una comunicación específicamente educativa. Este último punto es relevante para nuestra argumentación, pues ciertas propiedades de la propaganda (en tanto que fenómeno comunicativo) van a ser determinantes para distinguirla de la educación (también en tanto que fenómeno comunicativo).

\section{Propaganda y educación: tangencias y desencuentros}

El problema de las relaciones entre educación y propaganda es, en realidad, una variante de las relaciones, más generales, entre educación e ideología ${ }^{12}$, relaciones que

Cfr. García Aretio (1989), op. cit., 24.

Cfr. SARRAmOna, J. (2000): Teoría de la educación, Barcelona, Ariel, 17-25.

Cfr. Dewey, J. (1995): Democracia y educación. Traducción de Lorenzo Luzuriaga. Quinta edición. Madrid, Ediciones Morata, S. L., 2002, 15-17.

8 Aguaded GómeZ, J.I. (1995): «La Educación para la Comunicación. La enseñanza de los medios en el contexto iberoamericano», en Aguaded, J.I., y Cabero, J. (Dir.): Educación y Medios de Comunicación en el contexto iberoamericano, Sede Iberoamericana de la Rábida, Universidad Internacional de Andalucía, 42.

9 Cfr. Aguaded Gómez (1995), op. cit.

10 Cfr. Vera Vila, J. (1998): «Educación social e impacto educativo de los medios persuasivos: publicidad y propaganda», Revista de Educación, 316, mayo-agosto 1998, 199-200.

11 Cfr. BROWN CÉSAR, J. (2001): «Notas sobre un modelo de comunicación para el ámbito de la educación», Revista Latinoamericana de Estudios Educativos, XXXI (4), 19-54.

12 Cfr. Wooddy, C. H. (1935): «Education and Propaganda», Annals of The American Academy of Political and Social Science, 1935, 179, 227-239; Flores JARAMILLO, R. (1982): Los medios de comunicación y la educación permanente. Madrid, ORIENS, 26; BAUDELOT, Ch., y ESTABLET, R. (1999): «TEXTO 8. El aparato escolar y la reproducción», en Enguita, M. F. (editor) con la colaboración de Jesús M. Sánchez: 
son complejas ${ }^{13}$. Por otro lado, la discusión sobre las relaciones entre educación e ideología es considerablemente antigua ${ }^{14}$. Estas relaciones, así como la cuestión de los contenidos ideológicos en la educación, suponen campos demasiado complejos para ser abordados en este trabajo, que se enmarca disciplinarmente en el contexto de las Ciencias de la Información y la Comunicación. Desde un punto de vista comunicacional, nos limitaremos a las relaciones conceptuales establecidas entre la educación y esa forma particular de comunicación ideológica que es la propaganda. Teniendo en cuenta la dificultad que supone definir el concepto de ideología ${ }^{15}$, en el contexto de la comunicación propagandística, y siguiendo una de las definiciones aportadas por Terry Eagleton en Ideología, lo ideológico podría entenderse como

la promoción y legitimación de los intereses de grupos sociales con intereses opuestos [...]. Los intereses en cuestión deben tener alguna relevancia para el sostenimiento o puesta en cuestión de toda una forma de vida política. Aquí, la ideología puede contemplarse como un campo discursivo en el que poderes sociales que se promueven a sí mismos entran en conflicto o chocan por cuestiones centrales para la reproducción del conjunto del poder social [...]. Aquí, la ideología aparece como un tipo de discurso disuasorio o retórico más que verídico, menos interesado por la situación «tal como es» que por la producción de ciertos efectos útiles para fines políticos ${ }^{16}$.

Dado que la propaganda es un fenómeno más restringido que la ideología, resultaría relativamente más fácil aproximarse a las relaciones conceptuales existentes entre propaganda y educación. Al abordar estas relaciones, podemos distinguir dos planos: el plano práctico de la acción educativa, y el plano teórico.

\subsection{Plano de la acción educativa}

Los contactos entre propaganda y educación en el ámbito pedagógico evidencian al menos dos consecuencias prácticas (que son en realidad opuestas desde un punto de vista teórico): por un lado, la instrumentalización de la educación como un medio de

Sociología de la educación, Barcelona, Ariel, 97-104; REYZÁBAL, Mª V. (2002): Didáctica de los discursos persuasivos: la publicidad y la propaganda, Madrid, La Muralla, 93-95, 99-102; CAMPOS FiguerOA, J. A. (2005): «La escuela básica, formadora de líderes», Revista Educación en Valores, Año 2, 2 (4), JulioDiciembre 2005, 8-14.

13 Cfr. Dewey (1995), op. cit., 107-111; PÉREZ AlONSO-GETA, P. M. a (1990): «Manipulación», en VVAA, Filosofia de la educación hoy. Segunda edición. Madrid, Dykinson, 1991, 146-149; SANz FerNÁNDEZ, F. (2002): «13. Crítica a los sistemas de enseñanza», en Tiana Ferrer, A., Ossenbach Sauter, G., y Sanz Fernández, F. (Coords.): Historia de la educación (Edad Contemporánea), Madrid, Universidad Nacional de Educación a Distancia, 303-327; TRILLA, J. (1992): El profesor y los valores controvertidos, Barcelona y Buenos Aires, Paidós, 150-162.

14 Cfr. SedGwick, W. T. (1902): «The Modern Subjection of Science and Education to Propaganda», Science, New Series, Vol. XV, No. 367 (Jan. 10, 1902), 44-54.

${ }_{15}$ Cfr. Eagleton, T. (1997): Ideología. Traducción de Jorge Vigil Rubio. Barcelona, Paidós.

16 Ibidem, 53. 
propaganda; por otro, el uso de la educación como un medio de defensa del educando contra la propaganda.

\subsubsection{El uso propagandístico de la educación}

Desde el punto de vista de una instancia de poder, la educación es un medio propagandístico, y la práctica educativa evidencia que, históricamente, distintas instancias de poder han utilizado la enseñanza en su propio beneficio. En este sentido, puede hablarse de educación propagandística, que Adrián Huici Módenes distingue de la propaganda educativa. La primera consiste en la instrumentalización de la escuela por regímenes políticos (tanto democráticos como no-democráticos); la segunda, en el posible efecto educativo que pueden tener ciertas campañas de propaganda, como sucede en la tradición socialista de los siglos XIX y XX ${ }^{17}$. Tanto en este epígrafe como en el resto del artículo, el fenómeno que nos ocupará en su mayor parte será el de la educación propagandística.

Desde el punto de vista de la educación propagandística, la escuela puede suponer un ámbito de interés prioritario para el poder y sus propagandistas; sobre todo cuando los educandos se encuentran en edades tempranas. Como dijo Hans Schemm, líder de la Liga Nazi de Profesores: «Quienes tienen a la juventud de su lado controlan el futuro» ${ }^{18}$. Según señaló en 1918 una de las precursoras de la educación soviética, Lilina Zinoviev: «Tenemos que convertir a la joven generación en una generación de comunistas. Los niños, como la cera blanda, son muy maleables y deberían ser moldeados para convertirse en buenos comunistas $[\ldots]\rangle^{19}$. No es de extrañar, en este contexto, que la educación haya sido utilizada históricamente como medio de propaganda. De hecho, se ha señalado que, en el pasado, «adoctrinamiento» designaba frecuentemente la enseñanza en general ${ }^{20}$. Las instituciones educativas han sido históricamente los órganos dominantes del control social a través del control de la opinión pública ${ }^{21}$. Según el historiador Gabriel Jackson: «La enseñanza de historia en las escuelas de todos los países tiene la tarea de crear patriotas, no seres humanos» ${ }^{22}$.

El uso propagandístico de la educación, por otro lado, demuestra ser un instrumento al servicio de objetivos de poder diversos. Es más o menos lógico señalar el papel de la educación como medio de propaganda para el Estado ${ }^{23}$. Así, tanto en el fascismo ita-

\footnotetext{
17 Cfr. Huici Módenes (2010), op. cit., 160-163.

18 Citado en Welch, D. (1995): The Third Reich. Politics and Propaganda, Londres y Nueva York, Routledge, 63. Traducción propia.

19 Citada en Figes, O. (2000): La Revolución rusa (1891-1924). La tragedia de un pueblo. Traducción: César Vidal. Barcelona, Edhasa, 808.

20 Cfr. PÉrez AlONSO-GETA (1990), op. cit., 144.

21 Cfr. Glander, T. (2000): Origins of Mass Communications Research During the American Cold War, Mahwah, New Jersey / London, Lawrence Erlbaum Associates, Publishers, 28.

${ }_{22}$ Citado en REYZÁBAL (2002), op.cit., 100.

23 Cfr. Russell, B. (1996): The Collected Papers of Bertrand Russell, volumen 10. Londres y Nueva York, Routledge, 387.
} 
liano como en el nacional-socialismo alemán, el sistema educativo «en general fue penetrado ideológicamente por los principios del régimen (racismo, nacionalismo, imperialismo, etc.), afectando a las materias de estudio, a los libros de texto, al control y selección de los docentes y de los estudiantes, etc.» ${ }^{24}$. Sin embargo, el poder estatal no es el único que ha utilizado ideológicamente a las escuelas; también puede hablarse de una educación al servicio del poder económico ${ }^{25}$. La educación se ha utilizado asimismo como medio de propaganda bélica, como es el caso del Committee on Public Information de Estados Unidos durante la Primera Guerra Mundial ${ }^{26}$. También se ha tratado deliberadamente de convertir la escuela en un espacio de adoctrinamiento político-religioso $^{27}$, como evidencian los contenidos educativo-propagandísticos de la España franquista. La escuela también se ha utilizado a favor de la propaganda de la Reforma ${ }^{28}$. Incluso, se ha encontrado intención propagandística en materiales educativos de tipo matemático como la Cartilla aritmética antifascista publicada por el Ministerio de Instrucción Pública y Bellas Artes español en $1937^{29}$. También existe evidencia de propaganda de un país hacia otro a través de la educación ${ }^{30}$, lo que podría incluirse en la propaganda internacional. En definitiva, lo educativo se ha puesto al servicio de instancias de poder de distinta naturaleza a través de la Historia.

3.1.2. La educación como «profilaxis» anti-propagandística. Didáctica de los discursos propagandísticos

En el polo opuesto a la praxis educativa anterior se encuentran los esfuerzos que intentan prescribir el papel defensivo, «profiláctico» podríamos decir, que tiene la acción educativa como medio de enfrentarse críticamente a los contenidos propagandísticos. En este uso profiláctico o defensivo de la educación frente a la propaganda ${ }^{31}$ hay traba-

24 OSSENBACH SAUTER, G. (2002): «9. La educación en el fascismo italiano y el nacional-socialismo alemán», en Tiana Ferrer, A., Ossenbach Sauter, G., y Sanz Fernández, F. (Coords.): Historia de la educación (Edad Contemporánea), Madrid, Universidad Nacional de Educación a Distancia, 230.

${ }_{25}$ Cfr. Fones-Wolf, E. (2000): «Business Propaganda in the Schools: Labor’s Struggle Against the Americans for the Competitive Enterprise System, 1949-1954», History of Education Quarterly, 40 (3), otoño de 2000, 255-278.

26 Cfr. GlANDER (2000), op. cit., 5-11.

27 Cfr. MARTín ReQuero, M I. (2000): «Propaganda Política. Iconografía y Educación. Las imágenes de los textos escolares en la escuela franquista (1939-1975)», Publifilia, 3, Noviembre 2000, 29-47.

${ }_{28}$ Cfr. Ellul, J. (1969): Historia de la propaganda. Versión castellana: Rosa Moreno Roger. Caracas, Monte Avila Editores, 76.

${ }_{29}$ Cfr. Meavilla Seguí, V. (2006): «La cartilla aritmética antifascista (1937), un manual de educación matemática y propaganda política», Unión. Revista iberoamericana de educación matemática. Año 2006. Marzo de 2006, 5, 9-21.

30 Cfr. Young, J. P. (1982): «Intimate Allies in Migration: Education and Propaganda in a Philippine Village», Comparative Education Review, 26 (2) (June 1982), 231.

31 Cfr. Sproule, J. M. (1989): «Social Responses to Twentieth-Century Propaganda», en Smith, T. J. (ed.): Propaganda, Nueva York, Praeger, 11; GLANDER (2000), op. cit., 16, 19-20, 22-24. 
jos dedicados a enseñar en el aula la resistencia frente a la propaganda ${ }^{32}$. Según Bertrand Russell:

La propaganda juega su papel en todos los tipos de educación; ningún adulto puede evitar expresar sus aversiones y preferencias, y cuando se manifiestan en presencia de los jóvenes hacen el efecto de propaganda. Pero lo que debe preocupar al educador no es que haya o no propaganda, sino cuánta, de qué clase, y cómo está organizada; y también si hay que tratar de liberar a los niños, dentro de lo posible, de la influencia de la propaganda enseñándoles métodos que les permitan llegar a hacer un juicio imparcial ${ }^{33}$.

Frente a los efectos de la propaganda, autores como William W. Biddle han propuesto un programa educativo que perseguía hacer al estudiante «[...] critical of his own and other's thinking, and critical of the point of view which he is suppossed to accept. $^{34}{ }^{3}$. Una actividad educativa de esta naturaleza es crucial para intentar desembarazarse de los objetivos interesados de la propaganda, y la idea de fomentar un espíritu crítico en el educando es fundamental para ello: «El desarrollo del sentido crítico por la educación supone[...] liberarse de toda propaganda manipulativa, slogan, consigna, etc. $)^{35}$.

Así, las relaciones entre educación y propaganda también pueden enfocarse desde el punto de vista de la didáctica de los discursos propagandísticos ${ }^{36}$; didáctica que, si lo que se pretende es fomentar «la actitud crítica ante la manipulación y la demagogia de ciertos mensajes $[\ldots]\rangle^{37}$, se encuentra cerca del uso defensivo, anti-propagandístico, de la educación ${ }^{38}$.

\subsection{Plano teórico y conceptual}

Quizá podrían aportarse más ejemplos sobre el uso propagandístico de la educación (o, al menos, el intento de utilizar ideológicamente la educación con fines de poder), pero el objetivo de este trabajo no es enumerar los casos en que la educación ha sido instrumentalizada como propaganda -lo cual es un hecho empírico irrefutable-, sino establecer la hipótesis de que la educación no necesariamente es propaganda. No obstante, y en el plano teórico y conceptual en el que nos encontramos, la distinción entre

32 Cfr. Odegard, P. H. (1937): Reseña de Ellis, Elmer (ed.), Education Against Propaganda, The Public Opinion Quarterly, 1 (4), October 1937, 144-146.

33 Russell, B. (1988): La educación y el orden social. Traducción de José Vicuña y Ángeles Ortuño. Barcelona, Edhasa, 167-168.

34 Citado en GLANDER (2000), op. cit., 21.

35 PÉrEZ AlONSO-GETA (1990), op. cit., 149.

36 Cfr. REYZÁBAL (2002), op.cit., 21-27.

37 Ibidem, 21.

38 Teóricamente, también sería posible imaginar una didáctica que persiga que el alumno sea acrítico, dócil y conformista ante los mensajes propagandísticos; pero probablemente, en ese caso, sería redundante hablar de «didáctica de la propaganda»: lo que se hiciera en el aula sería, pura y simplemente, propaganda. 
propaganda y educación no ha sido siempre una constante. Comenzaremos, de hecho, por el punto de vista contrario: el que las identifica.

\subsubsection{La educación como propaganda}

Efectivamente, un punto de vista teórico posible es el que identifica educación y propaganda. Esta perspectiva conceptual se dirige frontalmente contra la idea de la educación como profilaxis antipropagandística: «It is commonly believed that formal education is a prophylactic against propaganda. On the contrary, I believe the opposite view is more realistic: education makes propaganda possible, helps propaganda accomplish its ends, and is in many ways itself a form of propaganda» ${ }^{39}$. Como observa Alejandro Pizarroso Quintero (uno de los principales historiadores de la propaganda en España): «El problema de identificar o disociar educación y propaganda es ciertamente polémico. [...] Por otra parte, a nuestro juicio, salvo lo que sea estrictamente enseñanza de técnicas -y no siempre-, la educación, entendida como un proceso complejo, es siempre propaganda» ${ }^{40}$.

Una posibilidad teórica cercana a la identificación consiste en partir de que las fronteras entre propaganda y educación son borrosas. Una expresión de este punto de vista se encuentra en La propaganda, nueva fuerza política, de Jacques Driencourt: «es imposible, e inútil, querer levantar barreras infranqueables entre la Educación y la Propaganda ${ }^{41}$. Otro ejemplo de perspectiva que difumina las fronteras entre los fenómenos estudiados es la concepción de Peter R. Hofstätter ${ }^{42}$, para quien la frontera entre educación y propaganda no es demasiado clara. El proceder del autor es empírico, y no considera que puedan existir diferencias esenciales entre ambos fenómenos: «Hace algún tiempo se llegó a afirmar que los libros de aritmética elemental usados en las escuelas del Tercer Reich [...] o de los Estados Unidos [...] difundían también doctrinas políticas (militarismo o capitalismo, respectivamente)» ${ }^{3}$; de estos y otros ejemplos deduce Hofstätter que la frontera entre educación y propaganda no es fácil de trazar. Pero no se plantea si tales ejemplos suponen un uso posible, propagandístico, de la educación, más que educación en sentido estricto.

\subsubsection{La perspectiva relativista}

Otro punto de vista teórico es el que hace depender la distinción entre propaganda y educación de un criterio subjetivo. El padre de las relaciones públicas, Edward L. Ber-

\footnotetext{
YounG (1982), op. cit., 218.

PiZARROSO QUiNTERO (1990), op. cit., 32-33.

DRIENCOURT (1964), op. cit., 49.

Cfr. HofstätTER, P. R. (1966): Introducción a la psicología social. Traducción por VERSUM. Revisión y notas por Oliver Brachfeld. Barcelona, Editorial Luis Miracle.

43 Ibidem, 304.
} 
nays, autor del libro de 1928 Propaganda ${ }^{44}$, señalaba en Cristalizando la Opinión Pública que la única diferencia entre propaganda y educación «está en el punto de vista. Abogar por lo que creemos es educación. Abogar por lo que no creemos es propaganda. Los dos nombres llevan consigo implicaciones sociales y morales. La educación es valiosa, recomendable, nos hace más lúcidos, más instruidos. La propaganda es insidiosa, deshonesta, engañosa» ${ }^{45}$. Desde este punto de vista, podría deducirse que la diferencia queda sujeta al juicio subjetivo de cada individuo; en otras palabras, al relativismo. Y desde una óptica tal, los educadores al servicio de la ideología de un estado totalitario podrían fácilmente decir que ellos no realizan «propaganda», sino «educación». La perspectiva relativista también podría ilustrarse con las ideas de uno de los principales teóricos de la propaganda, Harold D. Lasswell ${ }^{46}$. La siguiente afirmación lasswelliana es muy similar a la idea anterior de Bernays: «[...] propaganda is the transmission of attitudes that are recognized as controversial within a given community. Education is a process of transmitting skills and accepted attitudes ${ }^{47}$. Por consiguiente, la calificación de una comunicación como «propaganda» o como «educación» dependerá de un criterio tan cambiante como lo que esté «aceptado», o no, en una comunidad. Debe destacarse, además, el componente ideológico conservador de esta concepción funcionalista: si la educación se vincula a elementos como las «actitudes aceptadas», es evidente que el poder establecido tendrá una mayor facilidad para hacer pasar la comunicación de sus intereses ideológicos como «educación», cuando en realidad puede que no sea más que propaganda. En definitiva, la perspectiva relativista complica las posibilidades de clarificación conceptual.

\subsubsection{El punto de vista intermedio: la propaganda con efectos educativos}

Otro enfoque teórico de las relaciones propaganda-educación es el de los autores que mantienen posiciones «intermedias, afirmando que determinadas campañas propagandísticas (o publicitarias) tienen o han tenido efectos educativos sobre las masas ${ }^{48}$. Este enfoque se ajustaría a la expresión, ya citada, de propaganda educativa. Es, por supuesto, otra opción posible, pero presenta algunos inconvenientes, como el de la cuestión de los «efectos», que lleva al complicado terreno de los efectos de la propaganda y los medios de comunicación ${ }^{49}$. Como ha señalado Denis McQuail: «The entire

44 Cfr. BeRnAYs, E. L. (1928): Propaganda, New York, Horace Liveright.

45 Bernays, E. L. (1998): Cristalizando la Opinión Pública. Traducción de Ernesto Gómez Cereijo. Barcelona, Gestión 2000, 123.

46 Cfr. Pizarroso Quintero (1990), op. cit., 32-33.

47 LASSWELL, «The Study...», 3.

48 REYZÁBAL (2002), op.cit., 94.

49 Cfr. HeRreros ARCONADA, M. (1989): Teoría y técnica de la propaganda electoral (formas publicitarias), Barcelona, PPU, 40-41, 287; MARTín SALGADO, L. (2002): Marketing político, Barcelona y Buenos Aires, Paidós, 57; León, J. L. (2001): Mitoanálisis de la publicidad, Barcelona, Ariel, 50; NiMmO, D. (2001): Political Persuaders, New Brunswick y Londres, Transaction Publishers, 19-20; Moral, F., e 
study of mass communications is based on the assumption that the media have significant effects, yet there is little agreement on the nature and extent of these assumed effects ${ }^{50}$. Por otro lado, la perspectiva de los efectos implica la cuestión de dilucidar qué es un «efecto educativo», sobre todo si la comunicación que ha producido ese efecto procede de instancias de poder (que son las que generan la propaganda), por no hablar de la necesidad de deslindar dicho efecto de otras posibles consecuencias menos desinteresadas por parte del emisor.

\subsubsection{La perspectiva diferenciadora. Una propuesta}

El punto de vista en el cual encuadramos nuestra propuesta es el que concibe la educación como un fenómeno distinto a la propaganda. Una variante de este enfoque diferenciador es considerar, incluso, que educación y propaganda son opuestas en ciertos aspectos, o bien mutuamente excluyentes ${ }^{51}$. Así, por ejemplo, la propaganda, junto a la publicidad, también ha sido vista como la antítesis del discurso docente ${ }^{52}$.

Al menos desde la década de 1920 en Estados Unidos, existen intentos de diferenciar los fenómenos que nos ocupan ${ }^{53}$. Ya en 1927, Lasswell había señalado que había que distinguir la educación de la propaganda ${ }^{54}$. Nuestro trabajo pretende insertarse dentro de esta pretensión. Obviamente, esto implica también una crítica de las posturas que difuminan o eliminan las diferencias entre propaganda y educación. En primer lugar, consideramos que dichas posturas llevan a cabo una inducción incorrecta de los casos (innegables, por otro lado) en que la educación ha sido usada por parte del poder. En otras palabras, el hecho de que la relación comunicativa educador-educando se haya instrumentalizado propagandísticamente no significa que todo educador sea un propagandista. Como afirma María Victoria Reyzábal: «Una cosa es lo que la educación puede haber sido históricamente o, incluso, es y otra lo que defendemos que debe ser, es decir, un proceso sistemático encaminado a formar personas autónomas, críticas y creativas» ${ }^{55}$. Nos hallamos, en definitiva, ante usos diversos de la comunicación educativa; algunos de ellos podrán derivarse hacia intereses propagandísticos, pero otros de

Igartua, J. J. (2005): Psicología social de la comunicación. Aspectos teóricos y prácticos, Archidona (Málaga), Aljibe, 126.

50 MCQuAlL, D. (1983): McQuail's Mass Communication Theory. $4^{\text {th }}$ Edition. London, Thousand Oaks, New Delhi, Sage Publications, 2000, 416.

${ }_{51}$ Cfr. LuMLEY (1933), op. cit., 21.

52 Cfr. REYZÁBAL (2002), op.cit., 93-94. Consideramos que, desde un punto de vista intencional, la propaganda puede distinguirse de la publicidad comercial (cfr. PINEDA CACHERO, A. (2007): "Propaganda y publicidad comercial: un principio diferenciador", Questiones Publicitarias. Revista Internacional de Comunicación y Publicidad, I (12), 107-128. Disponible en Internet (20/04/2008): http://www.maecei.es/pdf/n12/articulos/Propaganda_y_publicidad_comercial_un_principo_diferenciador.p df). Por ello, no trataremos sobre esta última en el presente trabajo. Para un punto de vista sobre educación, propaganda y publicidad, véase VERA VILA (1998), op. cit., 193-213.

53 Cfr. Glander (2000), op. cit., 16-18.

54 Cfr. LASSWELL, «The Theory...», 628.

55 ReYZÁBAL, Mª V. (1999): Propaganda y manipulación, Madrid, Acento, 66. 
ellos apuntarán a objetivos más críticos y liberadores. Si se da a entender que se educa para consumir propaganda, estaría diciéndose algo así como que se fabrican bebidas para meter veneno en ellas. Incluso un autor como Noam Chomsky, tan proclive a presentar una perspectiva «monista» sobre la propaganda, mantiene la posibilidad de un sentido ideal de la educación, distinto a su uso propagandístico. Como señala el lingüista y activista político en una entrevista con David Barsamian titulada «El sistema de propaganda»:

Con respecto a lo que las escuelas enseñan para proteger a la gente contra esto, la respuesta es muy simple: nada. Las escuelas se sitúan más bien en el lado opuesto: forman parte del aparato de desinformación [...]. Se trata de instituciones pensadas para adoctrinar, fomentar actitudes de obediencia, bloquear el pensamiento independiente, que desempeñan una función institucional en un sistema de control y coerción. Las auténticas escuelas deberían proporcionar a la gente técnicas de autodefensa, lo cual significaría enseñarles la verdad sobre el mundo y sobre la sociedad; y no durarían mucho tiempo si lo hicieran ${ }^{56}$.

En segundo lugar, no hay que olvidar que, en ocasiones, la distinción de las barreras entre propaganda y educación puede ser parte de un esfuerzo interesado. Según señalaba Everett Dean Martin en 1929, la propaganda daña los esfuerzos del educador porque lleva al público a pensar «[...] that education and propaganda are the same thing, and thus to make an ignorant multitude believe it is being educated when it is only being manipulated. ${ }^{57}$.

En tercer lugar, es necesario tener en cuenta el contexto político que se estudia. La ecuación «propaganda = educación» puede fundamentarse y aplicarse con cierta capacidad predictiva, por ejemplo, en modelos de propaganda como el nazi o el leninista, donde ambos fenómenos se identifican. Pero tal identificación no tiene valor explicativo alguno, pues en modelos totalitarios como los citados todo funciona potencialmente como propaganda ${ }^{58}$, lo que hace innecesario especificar que la educación es un medio propagandístico más. Decir que en un estado totalitario la educación es propaganda no explica las relaciones entre ambas. Sería como decir que la publicidad comercial es fruto de la economía de mercado, y pretender que fuese algo más que una obviedad.

Un cuarto factor que nos lleva a profundizar en la perspectiva diferenciadora es la existencia de la educación en medios de comunicación (medios que son frecuentemente usados por los propagandistas; como afirmó Stalin: «El cine ayuda a la clase obrera

56 Chomsky, N. (1993): Crónicas de la discrepancia. Traducción de Luis Eguren. Madrid, Visor, 74. Chomsky también ha considerado posible que las escuelas se orienten hacia «proporcionar a los estudiantes algún medio para defenderse del asalto del aparato de propaganda masiva gubernamental[...]» (CHOMSKY, N. (2006): Los nuevos intelectuales. Traducción de Juan Ramón Capella. Barcelona, Grup Editorial 62, Ediciones Península, 154).

57 Citado en Glander (2000), op. cit., 17.

58 Cfr. Domenach, J.-M. (1951): «Leninist Propaganda», The Public Opinion Quarterly, 15 (2), (Summer 1951), 272-273. 
y a su partido a educar a sus trabajadores en el espíritu del socialismo, a organizar a las masas para la lucha por el socialismo, a elevar su nivel de cultura y su capacidad de lucha política» ${ }^{59}$ ). Según David Buckingham, «la educación mediática se propone desarrollar tanto la comprensión crítica como la participación activa», y gira «en torno al desarrollo de las capacidades críticas y creativas de los jóvenes ${ }^{60}$. Consideramos que el propio concepto de «educación para los medios de comunicación» (sobre todo en sus dimensiones críticas) supondría per se un principio de distinción conceptual entre educación y propaganda, dado que, si toda educación fuese propaganda, ¿qué sentido tendría implementar programas para que el educando formule criterios selectivos frente a las propuestas mediáticas? Si la educación es idéntica a la propaganda, esos programas estarían viciados desde la base; es decir, perseguirían un receptor crítico con la propaganda (entre otros discursos comunicativos) de una manera propagandística, con lo cual se plantearía una situación circular.

Si la identificación de propaganda y educación supone un error teórico, ¿cuál debe ser el criterio para distinguir estos fenómenos? Existen diferentes criterios para distinguir entre propaganda y educación ${ }^{61}$. Existe incluso alguna reflexión específica sobre los intentos de delimitar los roles respectivos de la educación y la propaganda, desde criterios distintos $^{62}$. Nuestros criterios conceptuales van a ser dos:

\section{(1) La intención comunicativa de la propaganda: poder e ideología}

El primer criterio es la intención comunicativa. Consideramos que la intención actúa como el principio causal que pone en marcha el proceso de la comunicación. Así, la pregunta clave es ¿por qué se genera una determinada comunicación? Intentamos adoptar un principio explicativo basado en las causas, en el porqué de los fenómenos. $\mathrm{Y}$ desde ese punto de partida podemos empezar a plantear la posible diferenciación de una forma de comunicación llamada «educación» y de otra que denominamos «propaganda», dado que los distintos factores causales (es decir, intencionales) que activan el proceso comunicativo son la clave de esa diferenciación.

Existen definiciones de la educación clasificables desde el punto de vista de la intencionalidad y desde el punto de vista del objetivo ideológico de la educación ${ }^{63}$. Nuestra perspectiva teórica va en esta línea: ¿qué intención persigue el educador? Si, como ya se ha visto, la educación puede considerarse un fenómeno comunicativo, basado en la relación establecida entre un educador (emisor) y un educando (receptor), y si partimos de que dicha relación estará regida por una intención comunicativa específica,

59 Citado en VÁzQuEz LiÑÁN, M. (2002): «El cine soviético y la creación del héroe», Razón y Palabra Número 28 Septiembre 2002. http://razonypalabra.org.mx/seduccion/2002/septiembre.html Web visitada el $31 / 3 / 2009$.

60 Buckingham, D. (2005): Educación en medios. Traducción de Isidro Arias. Barcelona, Paidós, 21.

61 Cfr. Ibidem, 17.

62 Cfr. WOODDY (1935), op. cit.

63 Cfr. García Carrasco, y GarCía del Dujo (1996), op. cit., 50, 47-48. 
formularemos la hipótesis de que existe una diferencia esencial entre la intención comunicativa educativa y la intención comunicativa propagandística. La cuestión clave radica en cómo pueden distinguirse estas dos intenciones; para ello, y dado que nuestro marco disciplinar es la Teoría de la Propaganda, observaremos el caso de la propaganda. Si se estudia la intención que persigue la comunicación propagandística, podremos hallar (a) el objetivo de una educación enfocada propagandísticamente, y, por negación, (b) el fin que debería seguir una acción pedagógica que pretendiese ser nopropagandística.

De la misma forma que se ha señalado que los objetivos de la publicidad son diferentes a los del educador ${ }^{64}$, podemos decir que los objetivos del propagandista son diferentes a los del educador. Esto radica en que la propaganda es un fenómeno comunicativo cuyo principio explicativo y definitorio es el poder ${ }^{65}$ : los emisores de propaganda son instancias, organizaciones e individuos que persiguen una posición de dominio y control sobre esferas relevantes de la estructura social, tales como el aparato estatal, la política económica, las creencias religiosas, etc. En este contexto, la propaganda se caracteriza porque las decisiones que hay en juego son trascendentes desde un punto de vista social: controlar las creencias religiosas de una colectividad, justificar la entrada en una guerra, reforzar una estructura política... son ámbitos de aplicación clásicos de la comunicación propagandística, y son asimismo esferas de actuación del poder organizado (poder religioso, poder político, etc.). Comunicativamente, la intención del emisor propagandista persigue instalar en los patrones cognitivos y conductuales del receptor una determinada representación de la realidad cuyo objetivo fundamental es satisfacer los intereses del emisor, y asegurarle a este último una posición de relevancia en la estructura social.

La intención de poder unifica asimismo las distintas manifestaciones y mensajes propagandísticos, más allá de los procedimientos, contenidos y medios empleados en la comunicación. Las instancias propagandísticas van a emplear cualquier tipo de recurso para lograr sus fines de poder. Y esa es la lógica que rige cuando el medio educativo se instrumentaliza propagandísticamente; el resultado es la educación propagandística, que supone la toma de partido deliberada del educador a favor de una instancia de poder. Según Jaume Trilla,

[...] la propaganda suele suponer una beligerancia explícitamente positiva e implícitamente negativa. De hecho, sólo se hace propaganda cuando el objeto se quiere presentar como superior a otros; cuando no ocurre así, el objeto simplemente «se da a conocer». Por eso, decimos que un maestro hace propaganda cuando presenta favorablemente una concepción política $[\ldots]^{66}$.

64 Cfr. Biasutto García, M. Á. (1995): «Desde el lenguaje publicitario hacia la acción didáctica», Comunicar, 5, octubre, 57.

65 Cfr. Pineda CACHERO, A. (2006): Elementos para una teoría comunicacional de la propaganda, Alfar, Sevilla; Huici MÓDENES (2010), op. cit.

${ }_{66}$ Trilla (1992), op. cit., 119. 
Si la propaganda es una comunicación de contenido ideológico y, sobre todo, fines de poder, las acciones educativas que no quieran incurrir en estos parámetros deberán evitar los fines de poder. Y esto debe aplicarse tanto a contextos políticos nodemocráticos como formalmente democráticos, ya que equiparar la educación propagandística con los estados totalitarios puede hacer que se olvide que los gobiernos «democráticos» también son susceptibles de hacer propaganda ${ }^{67}$, utilizando para ello medios como la educación. Sea cual sea el sistema político, en cuanto la educación se orienta deliberadamente hacia la inculcación de valores ideológicos favorables a una instancia de poder, se transforma automáticamente en propaganda; por lo tanto, una educación auténtica sería aquella que no predispone sus contenidos hacia la satisfacción de los intereses de instancias de poder organizadas, sean de la naturaleza que sean. En otras palabras, desde la perspectiva de la Teoría de la Propaganda, la educación adquiriría un carácter instrumental cuando es usada con una intención de poder. De la misma forma que, por ejemplo, una obra de arte ve subsumidos -0 , al menos, alterados- sus fines estéticos e incluso doctrinales cuando es planteada como apología del poder, la educación ve subsumidos sus fines formativos y críticos cuando es planteada como una herramienta de control social. Según afirmaba en 1989 Lorenzo García Aretio, «son mayoría los que consideran que la educación es esencialmente perfección del hombre, de la persona y supone un paso de una situación a otra, de un estado a otro, de lo que se es a lo que se debe sern ${ }^{68}$. En una educación propagandística, ese deber ser responde a modelos ideológicos que responden a intereses de poder: patriotismo, belicismo, racismo, etc.

Ahora bien, evitando la causa generadora de la comunicación propagandística (la intención de poder), la educación puede librarse de ser manipulada en ese sentido, y apuntar hacia objetivos de crítica, desarrollo y libertad. Objetivos que, por cierto, son incompatibles con la intención propagandística: la única crítica, el único desarrollo y la única libertad que fomentan las instancias de poder son la crítica, el desarrollo y la libertad que van en la dirección de sus intereses particulares. Por consiguiente, los ideales de una educación que fomente el libre desarrollo intelectual del educando se enfrentan inevitablemente con las constricciones de las necesidades del poder. Esta dialéctica es reconocida de algún modo en el siguiente fragmento de un decreto de 1884 del ministerio austríaco del culto y de la enseñanza, que considera que los maestros deben tener presente:

el principio fundamental de la enseñanza, válido para toda escuela, según el cual el deber del maestro es el de estimular todas las capacidades intelectuales de los niños y el de promover el feliz desarrollo del ánimo, pero que, precisamente por esta razón [...] también es el de evitar de la manera más atenta en las disciplinas humanísticas, y en particular en las históricas, todo lo que, aun siendo cientificamente válido y útil para la investigación y la enseñanza, en las escuelas primarias puede confundir las ideas de los niños y 
sacudir los fundamentos de sus convicciones religiosas y de su amor por la patria común, impartidos en la escuela ${ }^{69}$.

Queda claro que, desde la perspectiva de una instancia de poder, el estímulo de «todas las capacidades intelectuales de los niños» puede llegar a ser un problema, dado que dicho estímulo puede llegar a convertirse en una amenaza para los «fundamentos» de las creencias ideológicas que sostienen a los poderosos.

Consideramos que, a diferencia de este enfoque restrictivo de la enseñanza, la esencia de la educación es el desarrollo (dentro de ciertos cauces pedagógicos) del pensamiento libre del educando. Según John Dewey, un fin educativo «debe fundarse en las actividades y necesidades intrínsecas (incluyendo los instintos originales y los hábitos adquiridos) del individuo determinado que ha de educarse ${ }^{70}$. Por el contrario: «El vicio de los fines externamente impuestos tiene raíces profundas. Los maestros los reciben de las autoridades superiores; estas autoridades los aceptan de lo que es corriente en la comunidad. Los maestros los imponen a los niños. Como primera consecuencia, la inteligencia del maestro no es libre; está reducida a recibir los fines dictados desde arriba ${ }^{71}$. Una educación propagandística se ajustaría perfectamente a estos fines impuestos externamente, a la captura de la inteligencia del educador, y a la imposición a los educandos. Para autores como Karl Wilhelm von Humboldt o Dewey, la educación debe consistir en proporcionar las oportunidades necesarias para la realización personal $^{72}$, lo cual es muy distinto a proporcionar las ideas adecuadas para el sostenimiento de un sistema de poder determinado.

Por consiguiente, si se quiere que la educación no sea propagandística, el educador debe rehuir, ante todo, la promoción de valores pro-poder. No basta con afirmar que, para evitar que la escuela se haga «propaganda» de una idea política, hay que rehuir la unilateralidad y presentar diversas opciones ${ }^{73}$; sobre todo, porque la apelación a presentar esas opciones «diversas» puede encubrir un sistema de premisas donde las «opciones» suponen en realidad variantes de una misma estructura de poder. Lo que hay que hacer es presentar críticamente toda concepción ideológica que suponga o sostenga un sistema de poder. Además, el profesor que no desee incurrir en la lógica de la propaganda debe reprimir sus propias tendencias políticas personales, e intentar no promover a priori ninguna instancia de poder específica (partidos políticos, iglesias organizadas, patronales empresariales, etc.) en el contexto del aula; la deseabilidad o no de una determinada instancia o estructura de poder debe ser, en todo caso, fruto de la reflexión libre del educando. Por supuesto, el educador puede (por razones pragmáticas

69 Citado en ADLER, M. (1980): «El marxismo, la educación y la política», en Adler, M., El socialismo y los intelectuales. Edición a cargo de José Aricó. Traducción de Alfonso García y Manuel Planas. México D.F.; Madrid; Argentina; Bogotá, Siglo veintiuno editores, 205.

70 DEWEY (1995), op. cit., 98.

71 Ibidem, 99.

72 Cfr. BARSKy, R. F. (2005): Noam Chomsky. Traducción de Isabel González-Gallarza. Barcelona, Península, 28.

73 Cfr. TRILla (1992), op. cit., 120. 
de muy distinta naturaleza) pensar que no está mal promover valores que estén en la línea de un partido político determinado, de una iglesia determinada, de una élite económica determinada, etc.; no obstante, y en el marco teórico establecido en este trabajo, habría dejado de ser un educador para convertirse, simple y llanamente, en un propagandista.

En este punto, nuestra propuesta teórica conecta de nuevo con la crítica a las posiciones que diluyen las diferencias entre educación y propaganda. Quizá tenga sentido pensar que las escuelas «no pueden liberarse lo suficiente de las presiones de la ideología ${ }^{74}$, o que todo profesor va a estar determinado ideológicamente por el sistema de poder en el que se inscribe su acción educativa, pero también puede pensarse que existen esfuerzos cuya intención es el desarrollo del educando ${ }^{75}$. De la misma forma que la visión de la escuela como un simple reflejo del poder y la ideología dominante es una visión, que debe complementarse con otras perspectivas más abiertas a las posibilidades transformadoras de la educación ${ }^{76}$, la visión determinista de la educación como propaganda debe complementarse con una visión no-monista que admita la posibilidad teórica de una enseñanza no sesgada propagandísticamente.

$\mathrm{Si}$, como ya hemos apuntado, desde el punto de vista de la praxis una educación nopropagandística debería evitar el intento de beneficiar a instancias de poder (ya sea en contextos democráticos o no-democráticos), lo primero que debería hacer la acción docente es desarrollar una actitud escéptica ante el propio sistema social e institucional en que se ubica dicha acción. Si por educación se entiende, por ejemplo, «la formación consciente de las nuevas generaciones conforme a la cultura y al ideal de cada pueblo y época» ${ }^{77}$, se está presuponiendo un campo abonado para la propaganda, dado que dicha formación acorde a la «cultura» de cada pueblo puede admitir fácilmente las estructuras de dominación de cada «época» y sus instancias de poder. La apología de la propia cultura puede degenerar fácilmente en apología del poder dominante en esa cultura. Sólo un escepticismo radical respecto al poder puede depurar a la educación de la manipulación propagandística.

Teniendo en cuenta las relaciones más generales entre educación e ideología, nuestra perspectiva, al ser más concreta, se distancia teóricamente de los puntos de vista para los cuales todas las prácticas escolares se entienden como «prácticas de inculcación ideológica»; sobre todo cuando esa inculcación conduce necesariamente al sostenimiento de una forma de poder ${ }^{78}$. Probablemente, la ideología sea inerradicable de todo proceso educativo, pero eso no significa que todo proceso educativo sea necesa-

\footnotetext{
CHOMSKY, Los nuevos..., 156.

Cfr. García CARRASCO, y GarCía del Dujo (1996), op. cit., 51-52.

76 Cfr. SAnZ FernándeZ, F. (2002): «13. Crítica a los sistemas de enseñanza», en Tiana Ferrer, A., Ossenbach Sauter, G., y Sanz Fernández, F. (Coords.): Historia de la educación (Edad Contemporánea), Madrid, Universidad Nacional de Educación a Distancia, 320-325.

77 Ruiz Amado, citado en García ARETIO (1989), op. cit., 17.

78 BAudelot, Ch., y Establet, R. (1999): «TeXTo 8. El aparato escolar y la reproducción», en Enguita, M. F. (editor) con la colaboración de Jesús M. Sánchez: Sociología de la educación, Barcelona, Ariel,
} 103. 
riamente propagandístico. La propaganda no es un sinónimo de «discurso ideológico»; es un discurso ideológico donde lo importante es que las ideas políticas, sociales, etc. se encuentran mediatizadas y sometidas a fines de poder específicos (sostener un gobierno, fomentar una política económica sometida a intereses de élite, etc.). La primera labor del docente, por consiguiente, es evitar todo contenido ideológico que introduzca en el aula un sesgo favorable a los fines de cualquier instancia de poder organizada.

\section{(2) La relación formal comunicativa: monologismo versus dialogismo}

El criterio anterior versaba sobre la conexión entre intención comunicativa y contenidos comunicativos. Intenciones comunicativas distintas van a generar fenómenos comunicativos distintos, $\mathrm{y}$ a tenor de ello la educación puede diferenciarse de la propaganda. De manera complementaria, el tipo de relación comunicativa también supone un criterio diferenciador. En otras palabras, ¿cómo debe ser la relación comunicativa entre emisor y receptor? Un aspecto relevante de esta relación es la dirección del flujo de comunicación. En la propaganda, por mucho que se diga que se «escucha» al receptor, el flujo de la comunicación es unidireccional (desde el emisor propagandista hacia el receptor); en otras palabras, en la propaganda no hay un auténtico diálogo, dadas sus condiciones de generación comunicativa:

un diálogo implica una situación comunicativa de igualdad, donde el Emisor y el Receptor, en el mismo plano, se escuchan mutuamente. Ambos son emisores y receptores. Pero la propaganda no puede diluir las fronteras entre el Emisor - que porta el poder-y el Receptor-que está sujeto al poder-. Diluir esas fronteras equivaldría en cierto modo a diluir la legitimidad de la instancia de poder, y esa legitimidad, como puede inferirse de los mensajes propagandísticos, es el punto que no se cuestiona ${ }^{79}$.

La intención de poder, en otras palabras, restringe la cualidad dialógica de la comunicación: como afirma el pedagogo libertario Paulo Freire, el quehacer del dominador «no puede ser dialógico [...]. En el momento en que se hiciese dialógico, problematizante, o el dominador se habría convertido a los dominados y ya no sería dominador, o se habría equivocado ${ }^{80}$. Por ello, puede decirse que el discurso de un educadorpropagandista no es dialógico, sino monológico. La comunicación educativa, por el contrario, pretende una relación bidireccional entre emisor y receptor. Esta concepción bidireccional de la comunicación educativa se vincula con «el diálogo abierto, como opuesto a la manipulación del otro, que sólo lo considera «objeto» de mensaje» ${ }^{81}$. Quizá no sea casualidad que el modo dialógico de comunicación se ha considerado el modo óptimo para la educación ${ }^{82}$. Es interesante que sea también un modo directamente

79 PinedA CACHERO, Elementos..., 161-162.

80 Freire, P. (1997): Pedagogía del oprimido. Traducción de Jorge Mellado. Madrid, Siglo XXI, 163-164. El subrayado es nuestro.

81 SARRAMONA (2000), op. cit., 19.

82 Cfr. BROWN CÉSAR (2001), op. cit. 
opuesto a la lógica de la propaganda. Por consiguiente, a través de este criterio llegamos, no sólo a la distinción entre comunicación educativa y comunicación propagandística, sino a su oposición conceptual. Un modo dialógico (antipropagandístico) de comunicación debería superar el unilateralismo de la voz del emisor, y convertir la pedagogía de éste en la activación del instinto de conocimiento del educando. Estimular «la imaginación y la motivación de los alumnos» ${ }^{83}$ puede ser un recurso para una educación no-propagandística, siempre que esa imaginación se extienda al campo ideológico y de las relaciones de poder. Según Kerschensteiner: «La educación consiste en distribuir la cultura, para que el hombre organice sus valores en su conciencia y a su manera, de acuerdo con su individualidad» ${ }^{84}$; sin embargo, el educador-propagandista (que no está al servicio del desarrollo individual del educando, sino de intereses de poder ajenos) no va a permitir el cuestionamiento ideológico del poder, ni que «el hombre organice sus valores en su conciencia y a su manera». El educador no es sólo un propagandista cuando hace apología de gobiernos o instituciones políticas; comunicativamente, su labor propagandística también radica en encauzar el pensamiento racional y el instinto libre de conocimiento en la dirección de una ideología de poder.

Si la educación persigue «la obtención de una actitud crítica permanente» ${ }^{85}$, la propaganda persigue la supresión permanente de la actitud crítica hacia una determinada instancia de poder. En este sentido, el discurso propagandístico ofrece al receptor un mundo predeterminado, basado en los contenidos ideológicos de la instancia propagandista. Según el teórico de la propaganda Jacques Ellul:

To begin with, what is it that propaganda makes disappear? Everything in the nature of critical and personal judgment. Obviously, propaganda limits the application of thought. It limits the propagandee's field of thought to the extent that it provides him with readymade (and, moreover, unreal) thoughts and stereotypes. It orients him toward very limited ends and prevents him from using his mind or experimenting on his own. It determines the core from which all his thoughts must derive and draws from the beginning a sort of guideline that permits neither criticism nor imagination. More precisely, his imagination will lead only to small digressions from the fixed line and to only slightly deviant, preliminary responses within the framework ${ }^{86}$.

Por el contrario, la educación implica «la relación entre seres humanos donde siempre interviene la incertidumbre, gracias a la cual es posible hablar de libertad de elección en el sujeto que se educa» ${ }^{87}$. Como ha observado el historiador de la propaganda

83 Cfr. Robinson, K., con AronicA, Lou (2009): el Elemento. Traducción de Mercedes García Garmilla. Barcelona, Random House Mondadori, Grijalbo, 322.

84 Citado en García Aretio (1989), op. cit., 16.

85 Cirigliano, G. (1961): «Educación y propaganda», Archivos de Ciencias de la Educación 1961 (1), 48 .

86 Ellul, J. (1973): Propaganda. The Formation of Men's Attitudes. Traducción del francés de Konrad Kellen y Jean Lerner. Nueva York, Vintage Books, 169.

87 SARRAMONA (2000), op. cit., 14. 
Philip M. Taylor, «propaganda tells people what to think whereas education teaches people how to think» ${ }^{88}$.

\section{Conclusiones}

En este trabajo hemos intentado reflexionar sobre las condiciones bajo las cuales podría distinguirse a la propaganda de la educación, a partir de una determinada concepción de la propaganda. Nuestra propuesta al respecto es que puede establecerse una diferencia doble:

(a) Desde el punto de vista de la intención comunicativa, la propaganda es un fenómeno comunicativo cuyo objetivo gira en torno a la consecución, mantenimiento o refuerzo del poder; por consiguiente, la intención de una comunicación educativa auténtica no debe regirse por la intención de la propaganda, sino por el desarrollo libre del educando. Los contenidos de una educación nopropagandística no deberán disponerse hacia la satisfacción de los intereses de instancias de poder organizadas. Si, por el contrario, los contenidos ideológicos presentes en la educación son puestos deliberadamente al servicio del poder, la educación se transformaría en propaganda.

(b) Desde un punto de vista formal (relativo a la estructura de la relación comunicativa emisor-receptor), y a diferencia de la relación «emisor $\rightarrow$ receptor» típica de la propaganda, la comunicación educativa debe basarse en una relación «emisor $\leftrightarrows$ receptor». Una educación no-propagandística debe articular un flujo comunicativo dialógico entre emisor y receptor que anule o matice la imposición unidireccional de una ideología de poder por parte del educador, y que permita el libre desarrollo crítico y racional del educando.

En resumen, la clave para distinguir el fenómeno comunicativo que se denomina «educación» y el fenómeno comunicativo que se denomina «propaganda» radica en la concepción que se tenga de la educación respecto al poder. Si se tiene una concepción de la educación como generación, refuerzo o modificación de actitudes en beneficio de una determinada instancia de poder que domina una determinada estructura social, es superfluo emplear el término educación. Sería más clarificador hablar de educación propagandística, expresión ya citada, o incluso de propaganda a través de la educación. Si, por el contrario, se tiene una concepción de la educación como fomento del pensamiento crítico y libre, sin mediaciones ideológicas a favor del poder, hablaremos

88 TAYloR, P. M. (1990): Munitions of the Mind. A history of propaganda from the ancient world to the present day. New edition. Manchester y Nueva York, Manchester University Press, 1995, 14. 
de «educación» como fenómeno diferenciable de la propaganda, cuando no radicalmente opuesto a ella.

Desde un punto de vista práctico, los principios de diferenciación propuestos pueden ser útiles para la didáctica de los discursos propagandísticos, la educación en medios de comunicación y, en general, toda acción educativa donde entre en juego la consideración y discusión de ideologías de poder. En cualquier caso, el principio práctico a tener en cuenta es que una acción educativa crítica con el poder sólo es posible si es una acción educativa independiente del poder. Este es el punto de partida para que el docente escape de la manipulación propagandística.

Las ideas aquí expuestas son susceptibles de verificación empírica y corrección teórica ulteriores por parte de otros investigadores interesados en las relaciones existentes entre la comunicación propagandística y la comunicación educativa, y, en general, en la Teoría de la Propaganda. Desde una perspectiva disciplinar, consideramos interesante intentar aplicar a las relaciones entre publicidad comercial y educación el mismo patrón de conexiones y diferencias que puede establecerse entre propaganda y educación. Por otro lado, el intento de clarificar las relaciones entre educación y propaganda supone aproximarnos a una parte de ese problema más general que son las relaciones entre educación e ideología, considerablemente mucho más complejas.

\section{Referencias bibliográficas}

ADLER, M. (1980): «El marxismo, la educación y la política», en Adler, M., El socialismo y los intelectuales. Edición a cargo de José Aricó. Traducción de Alfonso García y Manuel Planas. México D.F.; Madrid; Argentina; Bogotá, Siglo veintiuno editores, 198-253.

AGUADED GÓMEZ, J.I. (1995): «La Educación para la Comunicación. La enseñanza de los medios en el contexto iberoamericano», en Aguaded, J.I., y Cabero, J. (Dir.): Educación y Medios de Comunicación en el contexto iberoamericano, Sede Iberoamericana de la Rábida, Universidad Internacional de Andalucía, 19-48.

BARSKY, R. F. (2005): Noam Chomsky. Traducción de Isabel González-Gallarza. Barcelona, Península.

BAUDELOT, Ch., y ESTABLET, R. (1999): «TEXTO 8. El aparato escolar y la reproducción», en Enguita, M. F. (editor) con la colaboración de Jesús M. Sánchez: Sociología de la educación, Barcelona, Ariel, 97-104.

BERNAYS, E. L. (1928): Propaganda, New York, Horace Liveright.

- (1998): Cristalizando la Opinión Pública. Traducción de Ernesto Gómez Cereijo. Barcelona, Gestión 2000.

BiAsutTo GarcíA, M. Á. (1995): «Desde el lenguaje publicitario hacia la acción didáctica», Comunicar, 5, octubre, 51-57.

BROWN CÉSAR, J. (2001): «Notas sobre un modelo de comunicación para el ámbito de la educación», Revista Latinoamericana de Estudios Educativos, XXXI (4), 19-54.

BuCKINGHAM, D. (2005): Educación en medios. Traducción de Isidro Arias. Barcelona, Paidós.

CAMPOS FigueroA, J. A. (2005): «La escuela básica, formadora de líderes», Revista Educación en Valores, Año 2, 2 (4), Julio-Diciembre 2005, 8-14. 
Chomsky, N. (1993): Crónicas de la discrepancia. Traducción de Luis Eguren. Madrid, Visor.

- (2006): Los nuevos intelectuales. Traducción de Juan Ramón Capella. Barcelona, Grup Editorial 62, Ediciones Península.

Cirigliano, G. (1961): «Educación y propaganda», Archivos de Ciencias de la Educación 1961 (1), 46-55.

DeweY, J. (1995): Democracia y educación. Traducción de Lorenzo Luzuriaga. Quinta edición. Madrid, Ediciones Morata, S. L., 2002.

Domenach, J.-M. (1951): «Leninist Propaganda», The Public Opinion Quarterly, 15 (2), (Summer 1951), 265-273.

DRIENCOURT, J. (1964): La propaganda, nueva fuerza política. Traducción castellana de Inés Oyuela de Estrada. Buenos Aires, Editorial Huemul.

EAgleton, T. (1997): Ideología. Traducción de Jorge Vigil Rubio. Barcelona, Paidós.

ElLuL, J. (1969): Historia de la propaganda. Versión castellana: Rosa Moreno Roger. Caracas, Monte Avila Editores.

- (1973): Propaganda. The Formation of Men's Attitudes. Traducción del francés de Konrad Kellen y Jean Lerner. Nueva York, Vintage Books.

FIGES, O. (2000): La Revolución rusa (1891-1924). La tragedia de un pueblo. Traducción: César Vidal. Barcelona, Edhasa.

FLORES JARAMILlO, R. (1982): Los medios de comunicación y la educación permanente. Madrid, ORIENS.

Fones-Wolf, E. (2000): «Business Propaganda in the Schools: Labor's Struggle Against the Americans for the Competitive Enterprise System, 1949-1954», History of Education Quarterly, 40 (3), otoño de 2000, 255-278.

FreIRE, P. (1997): Pedagogía del oprimido. Traducción de Jorge Mellado. Madrid, Siglo XXI.

GARCÍA ARETIO, L. (1989): La Educación, Madrid, Paraninfo.

GARcía CARrasco, J., y GARCÍA DEL Dujo, Á. (1996): Teoría de la educación. I. Educación y acción pedagógica, Salamanca, Ediciones Universidad de Salamanca.

Glander, T. (2000): Origins of Mass Communications Research During the American Cold War, Mahwah, New Jersey / London, Lawrence Erlbaum Associates, Publishers.

Herreros ArCONADA, M. (1989): Teoría y técnica de la propaganda electoral (formas publicitarias), Barcelona, PPU.

HofSTÄTTER, P. R. (1966): Introducción a la psicología social. Traducción por VERSUM. Revisión y notas por Oliver Brachfeld. Barcelona, Editorial Luis Miracle.

HuICI MóDENES, A. (2010): Guerra y propaganda en el siglo XXI. Nuevos mensajes, viejas guerras., Sevilla, Alfar.

Lasswell, H. D. (1927): «The Theory of Political Propaganda», The American Political Science Review, vol. 21, 1927, 627-631.

- (1969): «The Study and Practice of Propaganda», en Lasswell, H. D., Casey, R. D., y Smith, B. L. (eds.): Propaganda and Promotional Activities. An Annotated Bibliography, The University of Chicago Press, 3-27.

LEÓN, J. L. (2001): Mitoanálisis de la publicidad, Barcelona, Ariel.

LuMLeY, F. E. (1933): The Propaganda Menace, Nueva York y Londres, D. Appleton-Century Company, Inc.

MARTín REQUERO, Ma I. (2000): «Propaganda Política. Iconografía y Educación. Las imágenes de los textos escolares en la escuela franquista (1939-1975)», Publifilia, 3, Noviembre 2000, 29-47. 
MARTÍN SALGADO, L. (2002): Marketing político, Barcelona y Buenos Aires, Paidós.

MCQuAIL, D. (1983): McQuail's Mass Communication Theory. $4^{\text {th }}$ Edition. London, Thousand Oaks, New Delhi, Sage Publications, 2000.

MeAVILla SEGUí, V. (2006): «La cartilla aritmética antifascista (1937), un manual de educación matemática y propaganda política», Unión. Revista iberoamericana de educación matemática. Año 2006. Marzo de 2006, 5, 9-21.

Moral, F., e Igartua, J. J. (2005): Psicología social de la comunicación. Aspectos teóricos y prácticos, Archidona (Málaga), Aljibe.

Nimmo, D. (2001): Political Persuaders, New Brunswick y Londres, Transaction Publishers.

Odegard, P. H. (1937): Reseña de Ellis, Elmer (ed.), Education Against Propaganda, The Public Opinion Quarterly, 1 (4), October 1937, 144-146.

Ossenbach SAUTER, G. (2002): «9. La educación en el fascismo italiano y el nacionalsocialismo alemán», en Tiana Ferrer, A., Ossenbach Sauter, G., y Sanz Fernández, F. (Coords.): Historia de la educación (Edad Contemporánea), Madrid, Universidad Nacional de Educación a Distancia, 217-232.

PÉREZ Alonso-GetA, P. M. a (1990): «Manipulación», en VVAA, Filosofia de la educación hoy. Segunda edición. Dykinson, Madrid, 1991, 141-150.

PINEDA CACHERO, A. (2006): Elementos para una teoría comunicacional de la propaganda, Alfar, Sevilla.

- (2007): «Propaganda y publicidad comercial: un principio diferenciador», Questiones Publicitarias. Revista Internacional de Comunicación y Publicidad, I (12), 107-128. Disponible en Internet (20/04/2008):

http://www.maecei.es/pdf/n12/articulos/Propaganda_y_publicidad_comercial_un_principo _diferenciador.pdf

PIZARRoso QuINTERO, A. (1990): Historia de la propaganda. $2^{\mathrm{a}}$ edición, ampliada. Madrid, Eudema, 1993.

REYZÁBAL, Ma V. (1999): Propaganda y manipulación, Madrid, Acento.

- (2002): Didáctica de los discursos persuasivos: la publicidad y la propaganda, Madrid, La Muralla.

RoBInSON, K., con ARONICA, Lou (2009): el Elemento. Traducción de Mercedes García Garmilla. Barcelona, Random House Mondadori, Grijalbo.

Russell, B. (1988): La educación y el orden social. Traducción de José Vicuña y Ángeles Ortuño. Barcelona, Edhasa.

- (1996): The Collected Papers of Bertrand Russell, volumen 10. Londres y Nueva York, Routledge.

SANZ FERNÁNDEZ, F. (2002): «13. Crítica a los sistemas de enseñanza», en Tiana Ferrer, A., Ossenbach Sauter, G., y Sanz Fernández, F. (Coords.): Historia de la educación (Edad Contemporánea), Madrid, Universidad Nacional de Educación a Distancia, 303-327.

SARrAmona, J. (2000): Teoría de la educación, Barcelona, Ariel.

SEDGWICK, W. T. (1902): «The Modern Subjection of Science and Education to Propaganda», Science, New Series, Vol. XV, No. 367 (Jan. 10, 1902), 44-54.

Sproule, J. M. (1989): «Social Responses to Twentieth-Century Propaganda», en Smith, T. J. (ed.): Propaganda, Nueva York, Praeger, 5-22.

TAYLOR, P. M. (1990): Munitions of the Mind. A history of propaganda from the ancient world to the present day. New edition. Manchester y Nueva York, Manchester University Press, 1995. 
TRILLA, J. (1992): El profesor y los valores controvertidos, Barcelona y Buenos Aires, Paidós. VÁZQUEZ LiÑÁN, M. (2002): «El cine soviético y la creación del héroe», Razón y Palabra Número 28 Septiembre 2002. http://razonypalabra.org.mx/seduccion/2002/septiembre.html Web visitada el 31/3/2009.

VERA VILA, J. (1998): «Educación social e impacto educativo de los medios persuasivos: publicidad y propaganda», Revista de Educación, 316, mayo-agosto 1998, 193-213.

Welch, D. (1995): The Third Reich. Politics and Propaganda, Londres y Nueva York, Routledge.

WoodDy, C. H. (1935): «Education and Propaganda», Annals of The American Academy of Political and Social Science, 1935, 179, 227-239.

YounG, J. P. (1982): «Intimate Allies in Migration: Education and Propaganda in a Philippine Village», Comparative Education Review, 26 (2) (June 1982), 218-234. 